\title{
Liquid-liquid Extraction Separation of Manganese (II) and Tungsten (VI) by 4-butanoyl-3-methyl-1-phenylpyrazol-5-one in Chloroform
}

\author{
${ }^{* 1}$ Ehirim, A.I.C; ${ }^{2}$ Ibe, C. O; ${ }^{2}$ Achinihu, I .O. and ${ }^{1}$ Ogwuegbu, M.O.C. \\ ${ }^{\prime}$ Department of Chemistry, Federal University of Technology, Owerri, Nigeria. \\ ${ }^{2}$ Department of Chemistry, Alvan Ikoku Federal College of Education, Owerri, Nigeria. \\ *Corresponding Author: ikmil2002@yahoo.com.; Phone: +234-7030561903
}

\begin{abstract}
The extraction of manganese (II) and tungsten (VI) from aqueous solution using 4-butanoyl-3methyl-1-phenylpyrazol-5-one (HBPy) in chloroform was studied as a function of extractant's concentrations and $\mathrm{pH}$. The results indicate that the degree of extraction of Mn (II) and W (VI) is dependent on the extractant's concentrations by a factor of two (2). This means that two moles of the HBPy ligand anion were complexed by one mole each of the Mn(II) and W (VI) ions, indicating that the extracted species both have metal-ligand mole ratio of 1:2, hence the $\mathrm{Mn}(\mathrm{II})$ and $W(\mathrm{VI})$ complexes extracted are of composition, $\mathrm{Mn}(\mathrm{BPy})_{2}$ and $\mathrm{WO}_{2}(\mathrm{BPy})_{2}$ respectively. The extractant equilibrium constants are $\log K_{e x}=-0.36$ and -0.98 for the $\mathrm{Mn}(B P y)_{2}$ and $\mathrm{WO}_{2}(\mathrm{BPy})_{2}$ respectively, showing that the HBPy is a more effective extractant for Mn (II) than W (VI). Again, the metals are more quantitatively recovered from the aqueous solution at higher acidity (lower pH). The separation factor for these metals using the reagent is reported and shows that the metals can be separated effectively from their mixtures by proper adjustment of the $\mathrm{pH}$ of the medium.
\end{abstract}

Key words: Extraction, Pyrazolones, Manganese, Tungsten, Equilibrium constants, Coordination Chemistry.

\section{Introduction}

In mineral processing industry, achieving an optimum extraction of valuable mineral components is an extremely important goal. The processes of leaching, solvent extraction and flotation are the major methods of processing minerals under aqueous conditions in which coordination chemistry may play an important role, and in facilitating the realization of this goal. The success of some of these processes is ascribed to the ability of the chemical reagents to form stable coordination complexes with metal ions in the aqueous solution or on the surfaces of the mineral lattice. In solvent extraction, the extractant and masking reagents react with the metal ions to form principally coordination complexes which are either selectively extracted into the organic phase or retained in the aqueous raffinate. This is the basis underlying the concentration and purification of metal values by this process (Ogwuegbu \& Chileshe, 2000). Usually, extraction involves interaction between a metal ion in the aqueous solution, and a complexing agent, commonly a chelating agent, dissolved in an immiscible organic phase.

Among the numerous chelating agents examined for this purpose (as potential extractants), the 4-acyl derivatives of 1-phenyl-3-methylpyrazol-5-ones have received much attention (Uzoukwu \& Adiukwu, 1996). This is probably because the 4-acylpyrazolones form metal chelates that are highly soluble in most organic solvents and form highly stable neutral metal complexes that are principally hydrophobic (Marchetti \& Pettinari, 2005). Again, they are more efficient extractants for metal ions in strong acid solutions and are cheaper than the widely used 4,4,4-trifluoro-1-(2-thienyl)-1,3-butanedione, $\mathrm{C}_{4} \mathrm{H}_{3} \mathrm{~S}-\mathrm{COCH}_{2} \mathrm{COCF}_{3}$. Also, the acyl (R) substituent can be varied easily to optimize extraction and separation of metals (Uzoukwu \& Gloe, 2003). In view of this, a wide range of R substituted pyrazolones (fig. 1a) have been synthesized and used as potential extractants for metal ions in aqueous solution. Of all the 4-acylpyrazolones in use, 4-benzoyl-3-methyl-1-phenylpyrazol-5-one has been used extensively as efficient extraction reagent (Uzoukwu \& Ukeje, 1997); probably it forms more stable complexes with various metal ions than the others. The structures of the keto-enol tautomeric forms of the 4-butanoyl-3-methyl-1-phenylpyrazol-5-one (designated in this work as HBPy) are as shown in figure (1b) below.<smiles></smiles>

Fig.1(a) - Generic structure of 4-acyl-3-methyl-1-phenylpyrazol-5-one. 


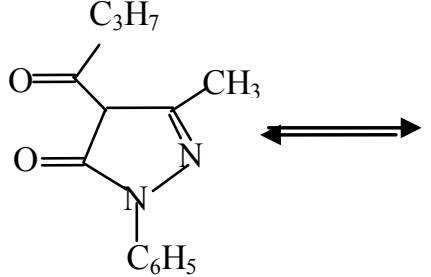

(keto form)

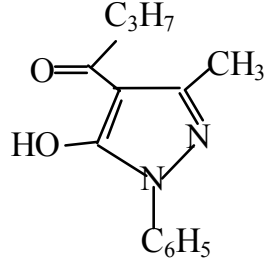

(enol form)

Fig.1(b) - Structures of the keto-enol tautomeric forms of the 4-butanoyl-3-methyl-1-phenylpyrazol-5-one.

Tungsten element, represented by the symbol, W (for Wolfram, its Greek name) belongs to group VI B in the Periodic table of elements, together with Chromium $(\mathrm{Cr})$ and Molybdenum (Mo). It has atomic number of 74 and atomic mass of 183.84. Its electronegativity on Pauling's scale is $1.70 \mathrm{eV}$. It has a density of $19.3 \mathrm{~g} / \mathrm{cm}^{3}$; and a high melting point of $3380{ }^{\circ} \mathrm{C}$. The element and its compounds have found applications in various areas thus: Sodium tungstate is a competitive inhibitor of molybdenum. Dietary tungsten reduces the concentration of molybdenum in tissues (Considine, 2005). One of the most stable chalcogen compounds of tungsten, $\mathrm{WS}_{2}$ (tungsten IV sulphide) is used as lubricant in a variety of applications, including automobile engines; lubricants described as containing "liquid tungsten" actually contain a suspension of very small $\mathrm{WS}_{2}$ particles (Averill et al., 2007). Because tungsten itself has an extraordinarily high melting point $\left(3380{ }^{\circ} \mathrm{C}\right)$, it is found use in making electric bulb filaments. Tungsten carbide (WC), one of the hardest compounds known, is used to make the tips of drill bits.

One of the principal sources of tungsten from which the metal is commercially produced is wolframite, $\left[(\mathrm{Fe}, \mathrm{Mn}) \mathrm{WO}_{4}\right]$ - containing mainly the metals: tungsten, manganese and iron. The classical method of extraction involves the leaching of the wolframite with strong sodium hydroxide, at about $100{ }^{\circ} \mathrm{C}$ in an autoclave to yield a solution of sodium tungstate, $\mathrm{Na}_{2} \mathrm{WO}_{4}$; thereby precipitating iron and manganese hydroxides.

$$
(\mathrm{Fe}, \mathrm{Mn}) \mathrm{WO}_{4}+2 \mathrm{NaOH}_{(\mathrm{aq})} \longrightarrow \mathrm{Na}_{2} \mathrm{WO}_{4}(\mathrm{aq})+\mathrm{Fe}(\mathrm{OH})_{2}+\mathrm{Mn}(\mathrm{OH})_{2} \ldots
$$

The leached solution is filtered, and tungsten is recovered from the alkaline solution as pure solid tungstenic acid, $\mathrm{H}_{2} \mathrm{WO}_{4}$ by treating with a strong acid (equal parts of commercial acid and water) (Xuin et al., 1986)

$$
\mathrm{WO}_{4}{ }^{2-}(\mathrm{aq})+2 \mathrm{H}^{+}{ }_{(\mathrm{aq})} \longrightarrow \mathrm{H}_{2} \mathrm{WO}_{4(\mathrm{~s})}
$$

Prior to the acid decomposition of $\mathrm{H}_{2} \mathrm{WO}_{4}$, other purification processes may be carried out on the tungstate, from which pure $\mathrm{WO}_{3}$ is obtained by heating (Kirth-Othmer, 1980).

The present study was carried out to determine the extractive effectiveness of 4-butanoyl derivative of 3-methyl-1-phenylpyrazol-5-one (HBPy) at its various concentrations on manganese (II) and tungsten (VI) and the effect of $\mathrm{pH}$ on the extraction. It is aimed at establishing a more efficient alternative method of separation between the two ions in their mixtures, especially in the wolframite ore of tungsten.

\section{Materials And Methods}

4-butanoyl- 3-methyl-1-phenylpyrazol-5one was synthesized by reacting 3-methyl-1-phenylpyrazol-5one with butanoyl chloride (Jensen, 1959; Ogwuegbu \& Masek, 1998 and Arinze, Daniel \& Ogwuegbu, 2012) and twice recrystallized from aqueous ethanol. Stock solutions of the ligand were prepared by dissolving $0.61 \mathrm{~g}$, $1.22 \mathrm{~g}, 1.83 \mathrm{~g}, 2.44 \mathrm{~g}$ and $3.05 \mathrm{~g}$ of 4-butanoyl-3-methyl-1-phenylpyrazol-5one in chloroform to get $250 \mathrm{~cm}^{3}$ of the solution (i.e., $0.01 \mathrm{M}, 0.02 \mathrm{M}, 0.03 \mathrm{M}, 0.04 \mathrm{M}$ and $0.05 \mathrm{M}$ respectively). Stock solutions of manganese (II) and tungsten (VI) were prepared by dissolving $0.99 \mathrm{~g}$ of $\mathrm{MnCl}_{2} .4 \mathrm{H}_{2} \mathrm{O}$ in water; $1.65 \mathrm{~g}$ of $\mathrm{Na}_{2} \mathrm{WO}_{4} .2 \mathrm{H}_{2} \mathrm{O}$ in $2 \mathrm{ml}$ $5 \mathrm{M} \mathrm{HCl}$ solution first, to generate only $\mathrm{WO}_{2}{ }^{2+}$ species (Bieluonwu, A. U., 1995) and then make up to $250 \mathrm{~cm}^{3}$ with distilled water, giving $0.02 \mathrm{M}$ solution of each.

\section{Extraction Procedure}

Studies on the extraction or recovery of the metals were carried out by agitating $5 \mathrm{ml}$ of the aqueous solution containing $5 \mathrm{mg} / 1$ of the Mn (II) and the W (VI) with $5 \mathrm{ml}$ of the various concentrations $(0.01-0.05$ $\mathrm{M})$ of the HBPy at a fixed $\mathrm{pH}$ of 2 for specific time of 30 minutes at $26^{\circ} \mathrm{C} \pm 0.5^{\circ} \mathrm{C}$. The study was also carried out by agitating the same $5 \mathrm{ml}$ of the $\mathrm{Mn}$ (II) and $\mathrm{W}$ (VI) solution at their various pH values of 2, 4, 6 and 8 with $5 \mathrm{ml}$ of $0.02 \mathrm{M}$ solution of the HBPy in chloroform for a specific time of 30 minutes using a mechanical shaker. For the $\mathrm{pH}$ studies, the aqueous solutions of the metallic ions were adjusted to different $\mathrm{pH}$ values using $\mathrm{HCl}$ and $\mathrm{Na}_{2} \mathrm{CO}_{3}$ to cover the $\mathrm{pH} 2$ to 8 . The $\mathrm{pH}$ values were measured with a digital $\mathrm{pH}$ meter Model pHS 25.The phases were separated at each extraction process and the concentrations of the Mn (II) and W (VI) remaining in 
the aqueous phase were determined spectrophotometrically using a Pye Unicam SP8-100 spectrophotometer at wavelength of $279.5 \mathrm{~nm}$ and $400.9 \mathrm{~nm}$ respectively. The metal extracted into the organic phase in each case was found by the difference (Uzoukwu \& Adiukwu, 1996).

\section{Extraction Equilibrium}

The extraction of the metal ion $\left(\mathrm{M}^{\mathrm{n}+}\right)$ from an aqueous phase using the ligand (HBPy), in the organic phase can be treated as follows:

$$
\mathrm{M}^{\mathrm{n}+}+\mathrm{xHBPy}_{(\text {org })} \underset{\mathrm{K}}{\mathrm{K}} \longrightarrow \mathrm{M}(\mathrm{BPy}) \mathrm{n}_{(\mathrm{org})}+\mathrm{xH}^{+} \ldots \ldots \ldots
$$

where; $\mathrm{K}_{\mathrm{ex}}$ is the extraction equilibrium constant, $\mathrm{M}=\mathrm{Mn}$ or $\mathrm{W}$

$$
\mathrm{K}_{\mathrm{ex}}=\left[\mathrm{M}(\mathrm{BPy}) \mathrm{n}_{(\mathrm{org})}\right] \cdot\left[\mathrm{H}^{+}\right]^{\mathrm{x}} /\left[\mathrm{M}^{\mathrm{n}+}\right] \cdot\left[\mathrm{HBPy}_{(\mathrm{org})}\right]^{\mathrm{x}}
$$

The Distribution ratio, $\mathrm{D}$, which is the ratio of the concentration of the metal into the organic phase to that in the aqueous phase, is given as:

$$
\mathrm{D}=\left[\mathrm{M}(\mathrm{BPy}) \mathrm{n}_{(\mathrm{org})}\right] /\left[\mathrm{M}^{\mathrm{n}+}\right]
$$

Substitution of $\mathrm{D}$ in equation (5) into equation (4) gives:

$$
\begin{aligned}
& \mathrm{K}_{\mathrm{ex}}=\mathrm{D} \cdot\left[\mathrm{H}^{+}\right]^{\mathrm{x}} /[\mathrm{HBPy}(\text { org })]^{\mathrm{x}} \\
& \mathrm{D}=\mathrm{K}_{\mathrm{ex}} \cdot[\mathrm{HBPy}(\text { org })]^{\mathrm{x}} /\left[\mathrm{H}^{+}\right]
\end{aligned}
$$

Taking the logarithms of both sides of equation (7) gives:

$$
\begin{aligned}
\log \mathrm{D}=\log \mathrm{K}_{\mathrm{ex}}+\log \left[\mathrm{HBPy}_{(\text {org })}\right]^{\mathrm{x}}-\log \left[\mathrm{H}^{+}\right]^{\mathrm{x}} . \\
\text { Or; } \quad \log \mathrm{D}=\log \mathrm{K}_{\mathrm{ex}}+\mathrm{x} \log \left[\mathrm{HBPy}_{(\mathrm{org})}\right]-\mathrm{x} \log \left[\mathrm{H}^{+}\right]
\end{aligned}
$$

Or; $\quad \log \mathrm{D}=\log \mathrm{K}_{\mathrm{ex}}+\mathrm{x} \log \left[\mathrm{HBPy}_{(\text {org })}\right]$
$\mathrm{H}=-\log \left[\mathrm{H}^{+}\right]$; equation $(9)$ can be re-written as:

since $\mathrm{pH}=-\log \left[\mathrm{H}^{+}\right]$; equation (9) can be re-written as:
\[ \log \mathrm{D}=\log \mathrm{K}_{\mathrm{ex}}+\mathrm{x} \log \left[\mathrm{HBPy}_{(\mathrm{org})}\right]+\mathrm{xpH} \]

From equation (10), therefore; plots of $\log \mathrm{D}$ versus $\log \left[\mathrm{HBPy}_{(\mathrm{org})}\right]$ and $\mathrm{pH}$ are linear, with slopes (x) equal to the number of moles of ligand involved in the complexation and the number of protons $\left(\mathrm{H}^{+}\right)$displaced from the acidified aqueous solution of the metal ions under study.

\section{Results and Discussion}

The results presented in Table 1 show that the distribution ratio, $\mathrm{D}$ is a function of $\mathrm{x}$ moles of the ligand concentrations as represented in equation (10). The values of $x$ determined from the slopes of the plots of log D versus $\log \left[\mathrm{HBPy}_{(\mathrm{org})}\right]$ as shown on fig. 2 are 1.76 and 1.74 for the Mn (II) and W (VI) respectively. This has indicated that the degree of extraction of Mn (II) and W (VI) is dependent on the extractant's concentrations by a factor of two (2). This also means that two moles of the HBPy ligand anion were complexed by one mole each of the Mn (II) and W (VI) ions, and representing a second power dependence of D on [HBPy], indicating that the extracted species both have metal-ligand mole ratio of 1:2. The compositions correspond to the formula, $\mathrm{Mn}(\mathrm{BPy})_{2}$ and $\mathrm{WO}_{2}(\mathrm{BPy})_{2}$ respectively. Similar reports have been made ( Onyedika, Arinze \& Ogwuegbu, 2013). In the metal ions under study, there is increase in the extraction process with increase in the concentration of the ligand; hence $0.05 \mathrm{M}$ of ligand gave highest extraction while $0.01 \mathrm{M}$ gave the least. The average $\mathrm{K}_{\mathrm{ex}}$ values obtained (Table 1) are -0.36 and -0.98 for the $\mathrm{Mn}(\mathrm{BPy})_{2}$ and $\mathrm{WO}_{2}(\mathrm{BPy})_{2}$ respectively, showing that butanoylpyrazolone (HBPy) proved a better extractant in the recovery of Mn (II) than W (VI) from their aqueous solutions. This could be as a result of the smaller size of the former, leading to a stronger bonding of the enol H (fig. 1b) of the HBPy.

\section{Dependence of Extraction on $\mathbf{p H}$}

The results presented in Table 2 show the distribution ratio, $\mathrm{D}$, as a function of $\mathrm{pH}$, while the plot is shown in fig. 3.

The plots of $\log \mathrm{D}$ versus $\mathrm{pH}$ at a constant concentration of $0.02 \mathrm{M}$ of the ligand (HBPy) presented in figure 3 are linear and show inverse relationship, inferring that higher acidity favours the extraction; alternatively, there is regression of extraction at higher $\mathrm{pH}$ values, probably due to metal hydrolysis, with the formation of one or more of a series of metal-hydroxo complexes (e.g., $[\mathrm{M}(\mathrm{OH})]^{\mathrm{n}-1},[\mathrm{M}(\mathrm{OH})]^{\mathrm{n}-2}, \ldots[\mathrm{M}(\mathrm{OH})]_{\mathrm{n}+1}$, etc). The observed fall in extraction at higher $\mathrm{pH}$ values could therefore be attributed to the formation of these non-extractable, hydrophilic, anionic products. Similar reports have been given elsewhere (Ogwuegbu, Oforka \& Spiff, 1996). The slopes of approximately $-2.0 ;\left\{\mathrm{Mn}(\mathrm{BPy})_{2}=-1.88\right.$; and -1.68 for $\left.\mathrm{WO}_{2}(\mathrm{BPy})_{2}\right\}$ obtained in fig. 3, indicate that $\mathrm{D}$ is inverse the second power dependent on hydrogen ion concentration of the aqueous phase at room temperature and that two moles of $\mathrm{H}^{+}$ions were released per mole of $\mathrm{Mn}$ (II) and W (VI) on the formation of the extractable complexes by the ligand. Again, this confirms the formation of simple metal chelates; $\mathrm{Mn}(\mathrm{BPy})_{2}$, and $\mathrm{WO}_{2}(\mathrm{BPy})_{2}$. Similar metal chelates have been observed by many investigators in the extraction of metals with acylpyrazolones (Pai et al, 2000; Bhattacharya et al, 2004). The average values of log $\mathrm{K}_{\mathrm{ex}}$ are: -6.91 and -7.48 for the $\mathrm{Mn}(\mathrm{BPy})_{2}$ and $\mathrm{WO}_{2}(\mathrm{BPy})_{2}$ respectively. 


\section{Separation of Mn (II) from W (VI)}

The separation of Mn (II) from W (VI) based on the $\mathrm{pH}$ adjustment was assisted by the observation that the metals were quantitatively extracted at certain $\mathrm{pH}$ values at which the other was extracted minimally. From the results in figure 3, it was possible to predict the separability or otherwise of one of the metal ions from the other using $0.02 \mathrm{M}$ HBPy in chloroform. The degree of separation was determined in terms of 'Separation Factor', $\mathrm{S}_{\mathrm{f}}$, defined as the ratio of the respective equilibrium constant $\left(\mathrm{K}_{\mathrm{ex}}\right)$ for the desired metal ion, $\mathrm{M}_{1}$ to that of the contaminant metal ion $\mathrm{M}_{2}$ (Ogwuegbu \& Oforka, 1994).

Thus: $\mathrm{S}_{\mathrm{f}}=\mathrm{K}_{\mathrm{ex}}(\mathrm{W}) / \mathrm{Kex}(\mathrm{Mn})=-7.48 /-6.91=1.08$

The S.F. value observed is comparable with those obtained for Thulium $(\mathrm{Tm})$ and Europium (Eu) using the ligands: 3-phenyl-4-benzoyl-5-isoxazolone $(\mathrm{HPBI}),(\mathbf{T m} / \mathbf{E u}=\mathbf{1 . 2 4})$; 3-phenyl-4-(4-fluorobenzoyl)-5isoxazolone (HFBPI), $(\mathbf{T m} / \mathbf{E u}=\mathbf{1 . 5 5})$ and 3-phenyl-4-(4-toluoyl)-5-isoxazolone (HTPI) $(\mathbf{T m} / \mathbf{E u}=\mathbf{1 . 8 0})$ (Rani, 2005).

\section{Conclusion}

Extraction of Mn (II) and W (VI) ions from aqueous solution using HBPy in chloroform has been studied. It is observed that the metals recovery depends on both the extractant concentrations and the $\mathrm{pH}$ of the aqueous Mn (II) and W (VI) solutions; but the former favours metal recovery more than the latter; hence increase in ligand concentrations is more pertinent in extraction process, with proper adjustment of $\mathrm{pH}$ of the aqueous metallic solution. The study has shown that the metal ions studied can quantitatively be separated from aqueous solutions in their mixture or in the presence of other metallic ions by proper adjustment of the extractant concentrations and $\mathrm{pH}$, thereby providing a clean method of purifying and concentrating ores or materials containing these metal ions for electrowinning.

Table 1-- Data on the extraction equilibria of the metal ions from their aqueous solutions at $\mathrm{pH} 2$ at various concentrations of HBPy ligand:

\begin{tabular}{|c|c|c|c|c|}
\hline \multirow{2}{*}{$\log [\mathrm{HBPy}]$} & \multicolumn{2}{|c|}{$\operatorname{Mn}(\mathrm{BPy})_{2}$} & \multicolumn{2}{c|}{$\mathrm{WO}_{2}(\mathrm{BPy})_{2}$} \\
\cline { 2 - 5 } & $\log \mathrm{D}$ & $\log \mathrm{K}_{\mathrm{ex}}$ & $\log \mathrm{D}$ & $\operatorname{Log~K}_{\mathrm{ex}}$ \\
\hline-2.00 & -0.03 & -0.03 & -0.87 & -0.87 \\
\hline-1.70 & 0.25 & -0.35 & -0.37 & -0.97 \\
\hline-1.52 & 0.41 & -0.54 & -0.07 & -1.02 \\
\hline-1.40 & 0.79 & -0.42 & 0.18 & -1.03 \\
\hline-1.30 & 0.95 & -0.44 & 0.37 & -1.03 \\
\hline
\end{tabular}

Average $\log \mathrm{K}_{\text {ex: }}: \mathrm{Mn}(\mathrm{BPy})_{2}=-0.36 ; \mathrm{WO}_{2}(\mathrm{BPy})_{2}=-0.98$

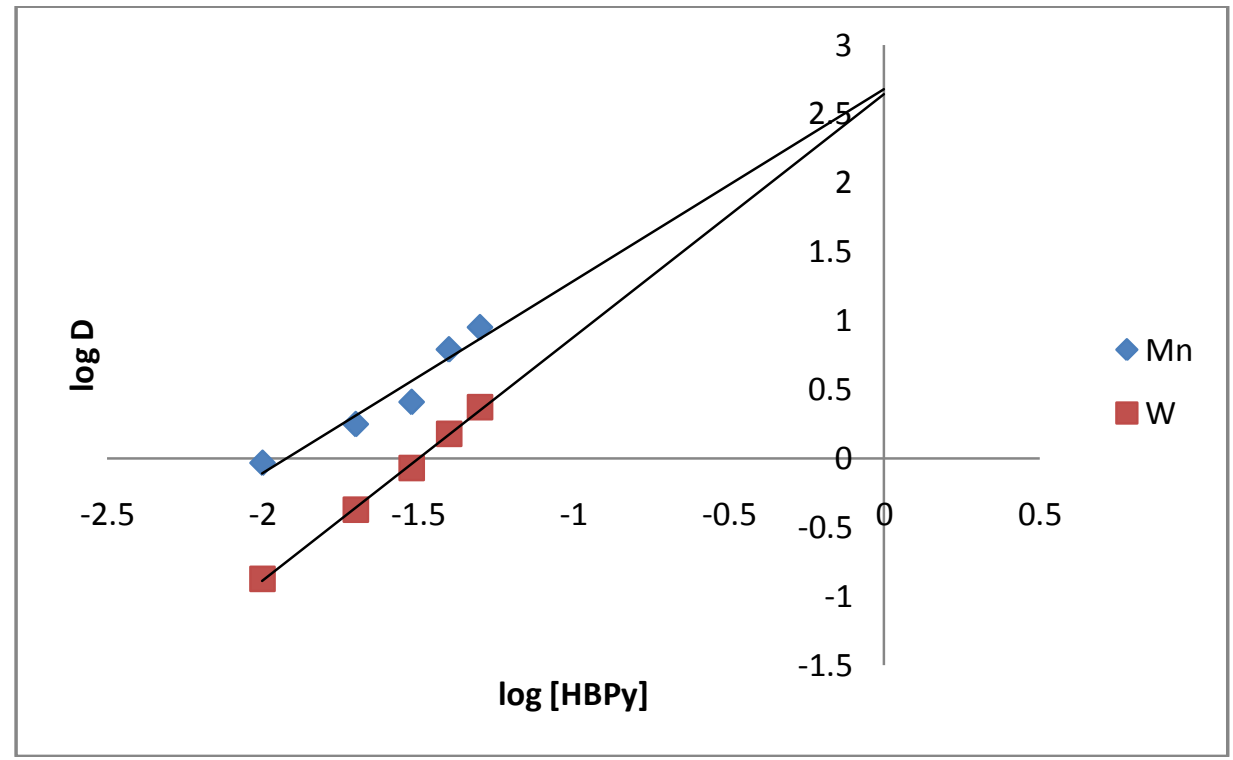

Fig. 2. Plots of log. of distribution ratio, D of the Mn (II) and W (VI) ions versus log. of [HBPy] at various concentrations at $\mathrm{pH} 2$. 
Table 2.-- Data on the logs of distribution ratios, D and extraction equilibria of the Mn (II) and W (VI) ions at different $\mathrm{pH}$ of their aqueous solutions using $0.02 \mathrm{M}$ of the HBPy ligand.

\begin{tabular}{|c|c|c|c|c|}
\hline & \multicolumn{2}{|c|}{$\mathrm{Mn}(\mathrm{BPy})_{2}$} & \multicolumn{2}{c|}{$\mathrm{WO}_{2}(\mathrm{BPy})_{2}$} \\
\hline $\mathrm{pH}$ & $\log \mathrm{D}$ & $\log \mathrm{K}_{\mathrm{ex}}$ & $\log \mathrm{D}$ & $\log \mathrm{K}_{\mathrm{ex}}$ \\
\hline 2 & 0.25 & -0.35 & -0.37 & -0.97 \\
\hline 4 & -0.10 & -4.71 & -0.72 & -5.32 \\
\hline 6 & -0.50 & -9.10 & -1.06 & -9.66 \\
\hline 8 & -0.87 & -13.47 & -1.38 & -13.98 \\
\hline
\end{tabular}

Average $\log \mathrm{K}_{\mathrm{ex}:}: \mathrm{Mn}(\mathrm{BPy})_{2}=-6.91$ and $\mathrm{WO}_{2}(\mathrm{BPy})_{2}=-7.48$.

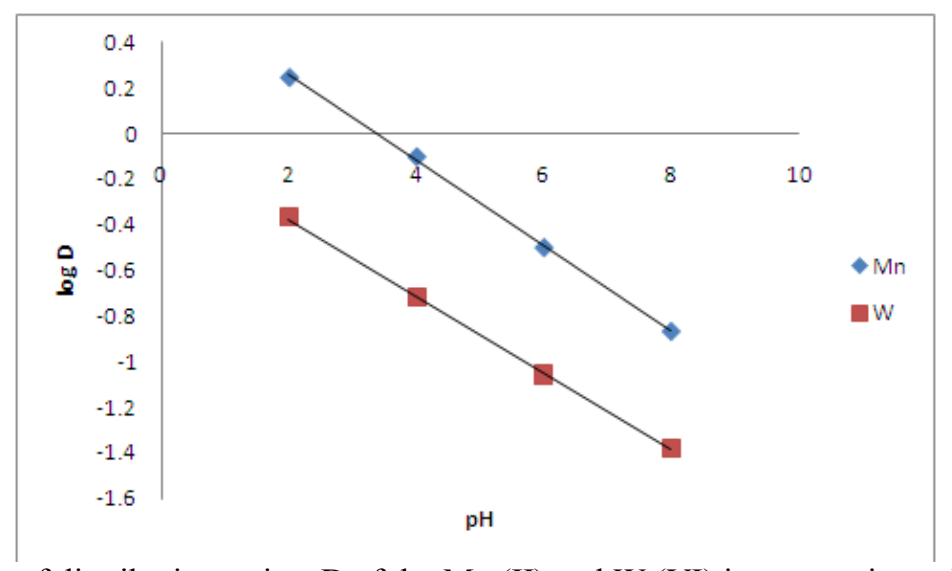

Fig. 3- Plot of logs. of distribution ratios, D of the $\mathrm{Mn}$ (II) and $\mathrm{W}$ (VI) ions at various pH of their aqueous solutions at a $0.02 \mathrm{M}$ HBPy concentration.

\section{References}

[1]. Arinze, J.C., Daniel, N.E. and Ogwuegbu, M.O.C. (2012). Synthesis and Characterization of p-nitrobenzoylpyrazolone-5 and its complexes of $\mathrm{Mn}(\mathrm{II}), \mathrm{Fe}(\mathrm{III}), \mathrm{Rh}(\mathrm{III}), \mathrm{W}(\mathrm{VI})$ and U(VI), Journal of Emerging Trends in Engineering and Applied Sciences, (JETEAS), 3(1), $61-68$.

[2]. Averill, B. and Elderedge, P. (2007). Chemistry; Principles, Patterns and Applications, Pearson Education Inc., New York, pp. 1055-1085.

[3]. Bhattacharya, A., Mohapatra, P.K, Banerjee, S, Basu, S. and Manchanda, V.K. (2004). Role of ligand structure and basicity on the extraction of uranyl isoxazolonate adducts, Solvent Extraction Ion Exch., 22, 13 - 29.

[4]. Bieluonwu, A. U. (1995). Spectrophotometric Determination of Vanadium (V) in aqueous medium using 4-benzoyl-3-methyl-1phenylpyrazol-5-one, AJST Series B, 8(1), 32 - 33 .

[5]. Considine, G. D. (2005). Zirconium, Molybdenum, Van Nostrand's Encyclopedia of Chemistry, Wylie-Interscience, New York, pp. $1138-1779$.

[6]. Jensen, B.S. (1959). The Synthesis of 1-phenyl-3-methyl-4-acylpyrazolones-5, Acta Chemica Scandinavia, 13,1668 - 1670.

[7]. Kirth-Othmer (1980). Encyclopedia of Chemical Technology, Vol. 23, $3^{\text {rd }}$ ed., John Wiley, New York, pp. $413-432$.

[8]. Marchetti, F., Pettinari, C., and Pettinari, R., (2005). Acylpyrazolone ligands: Synthesis, Structures, Metal Coordination Chemistry and Applications, Coordination Chemistry Reviews, 249, 2909-2945.

[9]. Ogwuegbu, M.O.C., Oforka, N. C. and Spiff, A. I. (1996). Enhanced extraction of nickel(II) with 3-methyl-4-(p-nitrobenzoyl)-5oxo-1-phenylpyrazole in the presence of benzyl alcohol, S.-Afr. Tydskr.Chem., 49(1/2), 26 - 30.

[10]. Ogwuegbu, M.O.C. and Chileshe, F. (2000). Coordination Chemistry in Mineral Processing, Min. Proc. Ext. Met. Rev., 21, 497 525 .

[11]. Ogwuegbu, M.O.C. and Maseka, K.K. (1998). Studies on the coordination complexes of Ca (II), Cd (II) and In (IV) with pnitrobenzoyl-oxo-pyrazole, Bull. Chem. Soc. Ethiop.,12(1), 27 - 33.

[12]. Ogwuegbu, M.O.C. and Oforka, N.C. (1994). Solvent Extraction Separation of Fe(III), Co(II), Ni(II) and Cu(II) from aqueous solution with 1-phenyl-3-methyl-4-(p-nitrobenzoyl)-5-pyrazolone, Hydromet., 34, 359 - 367.

[13]. Onyedika, G., Arinze, J. and Ogwuegbu, M. (2013). Studies on extraction behaviour of cobalt(II) with nitrobenzoylpyrazolone-5, Journal of Minerals and Materials Characterization and Engineeering, 1(3), $90-94$.

[14]. Pai, S.A., Lohithakshan, K.V., Mithapara, P.D. and Aggarwal, S.K. (2000). Solvent Extraction of Uranium (VI), Plutonium(VI) and Americium(III) with HTTA/HPMBP using mono- and bi- functional neutral donors: synergism and thermodynamics, J. Radioanal. Nucl. Chem., 245, $623-628$.

[15]. Rani, P. (2005). Investigations on the Solvent Extraction and luminescence of lanthanoids with mixtures of Heterocyclic $\beta$ diketones and various neutral oxo-donors, Ph.D. Thesis to Cochin University of Science and Technology, Kerala, India.

[16]. Uzoukwu, B. A. and Adiukwu, P. U. (1996). Kinetic studies on the recovery of lead (II) and lanthanum (III) from aqueous solution with xylene solution of 1-phenyl-3-methyl-4-benzoylpyrazolone, Indian Journal of Chemistry, 35A, 230 -232.

[17]. Uzoukwu, B.A. and Gloe, K. (2003). Extraction Studies and Synthesis of Molybdenum (VI) complexes of 4-adipoyl and 4-sebacoyl derivatives of bis(1-phenyl-3-methylpyrazolone-5), Indian J.Chem., 42A, 2727 - 2734.

[18]. Uzoukwu, B.A., Gloe, K. and Adiukwu, P.U. (2000). Metal (III) complexes of 4-acylbis(1- phenyl-3-methylpyrazolone-5): Synthesis and spectroscopic studies, Synth. React. Inorg. Met.-Org. Chem., 30(2), $335-347$.

[19]. Uzoukwu, B. A. and Ukeje, C.I. (1997). Extraction Studies of Chromium (VI) from aqueous solution with 1-phenyl-3-methyl-4butyrylpyrazolone, Indian J. Chem., 36A, 351-353.

[20]. Xuin, G.H., Yu, D.Y. and Su, Y.F. (1986). Leaching of Scheelite by hydrochloric acid in the presence of phosphate, Hydrometallurgy, 16 (1), $27-40$. 